\title{
Impartial Witness
}

National Cancer Institute

\section{Source}

National Cancer Institute. Impartial Witness. NCI Thesaurus. Code C142577.

A person who is independent of the trial, who cannot be unfairly influenced by people involved with the trial, who attends the informed consent process if the subject or the subject's leg ally acceptable representative cannot read, and who reads the informed consent form and any other written information supplied to the subject. (ICH) 